\title{
APLICACIÓN DE LA TÉCNICA DE TOMOGRAFÍA ACÚSTICA PARA LA VISUALIZACIÓN Y ESTIMACIÓN DE LA DENSIDAD DE MICROFRACTURAS EN MUESTRAS DE AFLORAMIENTO
}

Luis A. Gómez-Luna ${ }^{1}$; Jenny M. Carvajal-Jiménez ${ }^{1}$; Luis F. Ramírez-Silva ${ }^{1}$

DOI: http://dx.doi.org/10.18273/revbol.v38n1-2016009 (c) (1) $\Theta$

Forma de citar: Gómez-Luna, L.A., Carvajal-Jiménez, J.M., Ramírez-Silva, L.F. 2016. Aplicación de la técnica de tomografía acústica para la visualización y estimación de la densidad de microfracturas en muestras de afloramiento. Boletín de Geología, 38 (1): 165-181.

\section{RESUMEN}

Este trabajo presenta el desarrollo de una metodología para estimar el volumen de microfracturamiento en rocas, utilizando la técnica de tomografía acústica. Se utilizaron cristales piezoeléctricos como transductores para la generación de ondas acústicas secundarias o de corte a través de muestras de estudio. El tiempo de propagación de la onda es obtenido utilizando tratamiento digital de señales en MATLAB y finalmente se obtiene las distancias de cada una de las trayectorias entre los cristales, de esta manera se almacenan los valores de velocidad de onda en arreglos numéricos matriciales. La técnica empleada en este trabajo consiste en realizar tomografía acústica en función de la velocidad de la onda de corte, donde se logra diferenciar la matriz y las microfracturas de las rocas analizadas, a partir del contraste de las velocidades. Las imágenes tomográficas se generan a través de la renderización de las matrices de velocidades en MATLAB. Para poder validar esta investigación fue necesario utilizar plugs sintéticos de concreto como modelos controlados, donde se simularon discontinuidades por medio de inclusiones huecas hechas con prototipos de cauchos; finalmente los resultados obtenidos, muestran un error máximo de $7.06 \%$ fundamentando la confiabilidad de la técnica generada.

Palabras clave: densidad de microfractura, ondas acústicas, tomografía acústica.

\section{APPLICATION OF A NEW TECHNICAL OF ACOUSTIC TOMOGRAPHY FOR THE VISUALIZATION AND ESTIMATION OF THE MICROFRACTURES IN OUTCROP SAMPLES}

\begin{abstract}
This work presents the development of a methodology to estimate microfractures density in rocks, using acoustic tomography technique. The piezoelectric crystals were used as transductors for the generation of the acoustic shear kind waves, through study cores. The propagation time of the wave is obtained using digital signal processing in MATLAB and finally the distances of each paths is obtained, thus the wave velocity values are stored in numerical arrays. The technique used in this work is to perform acoustic tomography in function of the shear wave velocity, where the rock matrix and microfractures are differentiated and analyzed from contrasts of velocities. The tomographic images are generated through rendering matrices of velocity in MATLAB. In order to validate this research was necessary to use synthetic cements plugs as controlled models, where the discontinuity was simulated through hollow inclusions made with rubber prototypes; finally the obtained results show a maximum of $7.06 \%$ of error, baseing the reliability of the generated technique.
\end{abstract}

Keywords: Microfractures density, acoustic waves, acoustic tomography.

\footnotetext{
${ }^{1}$ Grupo de Investigación Estabilidad de Pozo. Instituto Colombiano del Petróleo. ICP - ECOPETROL S.A, luis.gomez@ wellborestability.org
} 


\section{INTRODUCCIÓN}

Considerar la presencia de microfracturas en la caracterización de yacimientos petrolíferos se ha convertido últimamente en un requerimiento importante, tanto que es imposible ignorar este parámetro debido a la tendencia de generar bajos desempeños técnico-económicos en las operaciones; éstos se deben principalmente al aumento de los Tiempos No Productivos (NPT) ocasionados por perdidas de fluido de circulación en la perforación y desaprovechamiento del medio efectivo de alta permeabilidad secundaria en el momento de la producción de hidrocarburos.

El aporte generado con esta investigación es contribuir a caracterizar de manera más puntual la existencia de microfracturas mediante una metodología propuesta, en este caso, utilizando muestras obtenidas de afloramientos, las cuales fueron analizadas en condiciones normales en el Laboratorio de Mecánica de Rocas del Instituto Colombiano del Petróleo (ICP - ECOPETROL S.A.). El futuro de este estudio se proyecta en analizar muestras de yacimiento a condiciones in situ.

Partiendo de investigaciones realizadas anteriormente en el ICP (Rueda, 2006), esta investigación propone un parámetro y/o valor denominado "densidad de microfractura", el cual estima cuantitativamente la presencia de microfracturas; éstas son definidas por Hooker et al. (2009) como discontinuidades con aperturas menores a $1,2 \mathrm{~mm}$ en rocas. Este parámetro específicamente es la relación del volumen de las microfracturas respecto al volumen analizado de la muestra de roca estudiada.

Aplicando técnicas geofísicas como la tomografía acústica, se ha creado una particular técnica para caracterizar la parte matricial y microfracturada en función de la velocidad de onda de corte (onda S), generando imágenes tridimensionales por medio de rutinas programadas en MATLAB; esta herramienta ha sido fundamental para la visualización y cuantificación de la densidad de microfracturas en las muestras rocas extraídas de los afloramientos, y realizar su validación en plugs sintéticos de concreto.

La técnica consistió en realizar inversión de ondas acústicas (ondas S) por medio de una abrazadera de acero con cristales piezoeléctricos adheridos con epoxico de plata, de esta forma también se evalúa la instrumentación general de adquisición acústica (pruebas ultrasónicas) y por ende la capacidad de resolución de tomografía acústica $(0,62 \mathrm{~mm})$ que se puede generar en el Laboratorio de Mecánica de Rocas del Instituto Colombiano del Petróleo, aportando a la generación de innovación y tecnología del ICP-ECOPETROL S.A.

\section{METODOLOGÍA}

\section{Diseño}

El objetivo principal de esta investigación es estimar la densidad de microfracturas en las rocas a partir de la integración del tiempo, velocidad y frecuencia como parámetros de ondas de acústicas con el fin de disminuir la incertidumbre en la caracterización de rocas naturalmente fracturadas. Para cumplir con el objetivo propuesto se planteó hacer inversión de ondas acústicas por medio de cristales piezoeléctricos (PZT), los cuales a través de una excitación eléctrica por medio de un generador de pulsos convierte pulsos eléctricos en mecánicos (ondas acústica) dependiendo del tipo de cristal (compresional o de corte) y viceversa. La onda acústica viaja por el medio rocoso y su tiempo de viaje es cuantificado en el osciloscopio, por lo general es el orden de los microsegundos. De acuerdo con las teorías de Potts (1993) e Imhof (2008) sobre propagación de onda, entre más anisótropo sea el medio, la onda tendrá un mayor tiempo de viaje ya que tiene que sortear el camino donde exista menos oposición a la propagación (FIGURA 1).

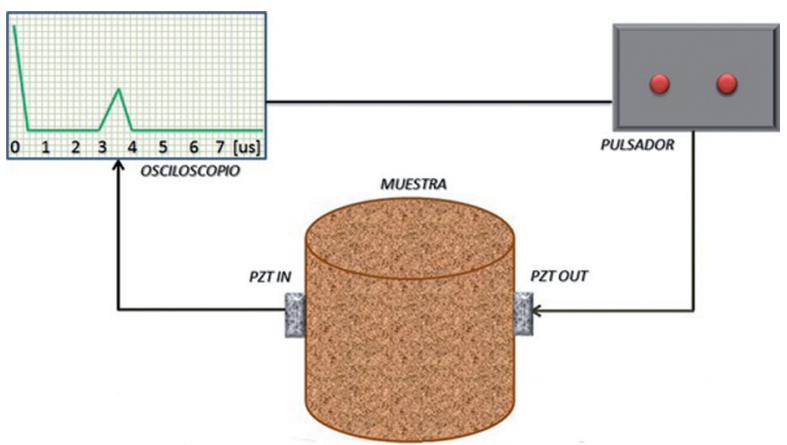

FIGURA 1. Representación gráfica de la aplicación de prueba ultrasónica utilizando cristales piezoeléctricos.

Los cristales utilizados fueron de tipo de corte, cuya frecuencia es de $600 \mathrm{KHz}$. Este parámetro es fundamental ya que a mayor frecuencia menor es la longitud de onda y por ende se pueden detectar anomalías de menor escala. La interacción entre las ondas acústicas y las anomalías depende principalmente del tamaño de anomalías y de la longitud de onda de la propagación. La longitud de onda determina la capacidad de detectar anomalías por parte de una onda en un medio, si la longitud de onda es mayor que la dimensión de la anomalía, ésta atravesará al material como si fuera un medio continuo; si es menor, la onda detectará la anomalía. 
Esta técnica de tomografía acústica propone utilizar una abrazadera de acero inoxidable de $0,2 \mathrm{~mm}$ de espesor y $6 \mathrm{~mm}$ de ancho, cubriendo el diámetro de las muestras de $31,75 \mathrm{~mm}$ (1,25 pulgadas); además utilizar PZT tipo onda S de $600 \mathrm{KHz}$ y de geometría cuadrada de $5 \mathrm{~mm}$ de lado. Los PZT se adhieren a la abrazadera con epóxico de plata garantizando que la vibración propague en la abrazadera y ésta a su vez en la roca, finalmente se adhirieron 8 PZT con espacios de $45^{\circ}$ (FIGURA 2).

La propagación acústica consiste en que todos los PZT son emisores y receptores en sus respectivos turnos, es decir, un PZT es emisor hacia los demás y cuando complete la ronda, deja de ser emisor y se convierte en receptor, cediendo el turno al siguiente. El objetivo es realizar un enmallado de trayectorias de señales (FIGURA 3) y cuantificar la distancia de cada una, en total se generan 56 trayectorias.

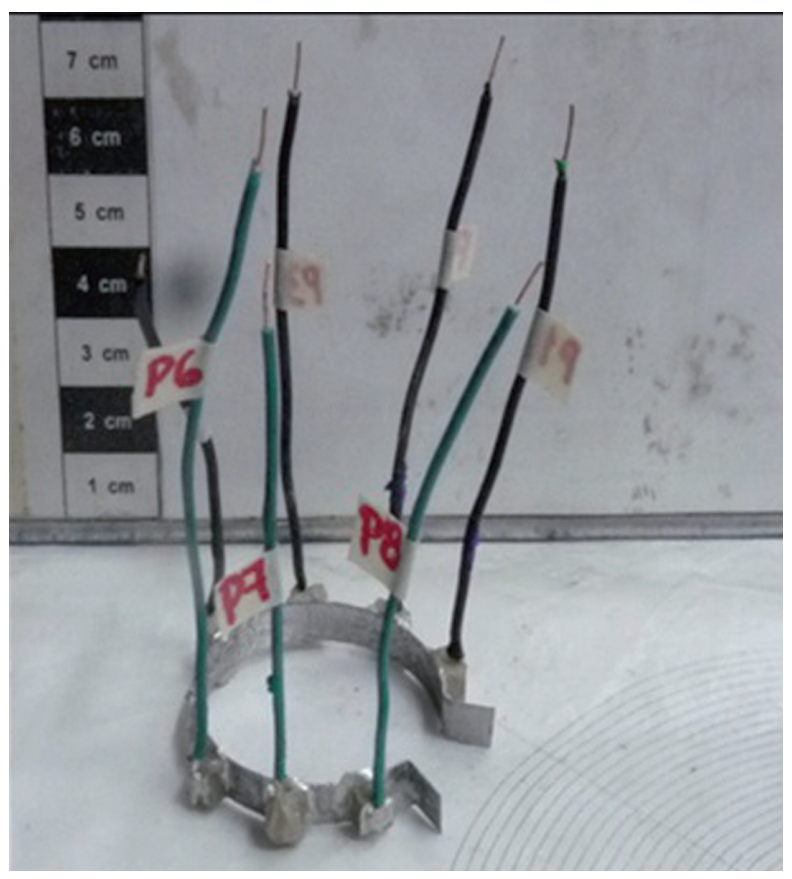

FIGURA 2. Abrazadera PZT tipo Onda S

Una vez cuantificado el tiempo de viaje de una señal y su respectiva trayectoria se procede a calcular la velocidad de onda. Mediante una rutina programada creada en el Laboratorio de Mecánica de Rocas del Instituto Colombiano del Petróleo, se genera una matriz numérica cuadrada de 51x51 pixeles con el fin de almacenar toda los valores de velocidad de onda $\mathrm{S}$ en cada uno de los pixeles de la matriz, sin embargo, solo se tienen en cuenta el área de pixeles que se encuentran dentro de la circunferencia demarcada por la trayectorias de las señales, ya que verdaderamente representa la sección transversal analizada de la muestra.

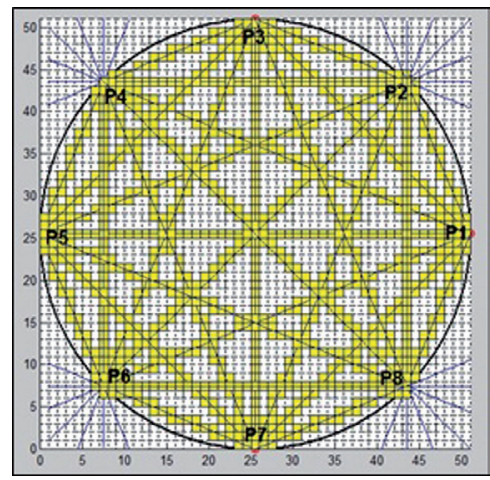

FIGURA 3. Enmallado de trayectorias

Posteriormente se procesa la sección circular de la matriz numérica utilizando rutinas a partir de MATLAB, el resultado son las imágenes tomográficas en 2,5 D cuando es una sola sección transversal, cuando es un conjunto de secciones generadas por el barrido vertical de la abrazadera se genera una renderización en 3,5 D; de esta forma se obtiene la Tomografía Acústica $2,5 \mathrm{D}$ y $3,5 \mathrm{D}$. Estas rutinas fueron programadas para esta investigación. La nomenclatura $2,5 \mathrm{D}$ y $3,5 \mathrm{D}$ se ha adaptado debido a que solo se tiene en cuenta como dimensiones las coordenadas X, Y y Z, siendo la velocidad una propiedad que se le asigna a un punto coordenado, más no es una dimensión.

Conociendo que las ondas acústicas son más rápidas en los sólidos y menos rápidas en los líquidos y gases; en el caso de la onda $\mathrm{S}$, no se propaga en fluidos, por lo tanto, contorneará las discontinuidades que no son sólidas aumentando el tiempo de propagación y por ende disminuyendo la velocidad, estos cambios se verán reflejados en el procesamiento de imágenes (renderización) a partir de las matrices numéricas mediante un gradiente de colores, establecido entre los valores mínimos y máximos de las velocidades.

\section{Muestras}

Las rocas muestreadas y recolectadas en los afloramientos (formaciones) son sedimentarias de tipo detríticas y químicas, areniscas y calizas, respectivamente. Los puntos de muestreo para la arenisca fueron en la Formación Tambor (Km 5 vía Lebrija - La Renta), y para la caliza la Formación La Luna (quebrada La Sorda), ambas en el departamento de Santander, Colombia (FIGURA 4).

Estadísticamente, el evento se centra en la obtención de muestras con microfracturas, por lo tanto el tipo de muestreo es probabilístico de carácter estratificado ya que las muestras se toman aleatoriamente dentro de un estrato geológico definido (afloramiento). La extracción se basó en utilizar un equipo portátil que saca núcleos con brocas de diámetro interno de 1,25 pulgadas. 


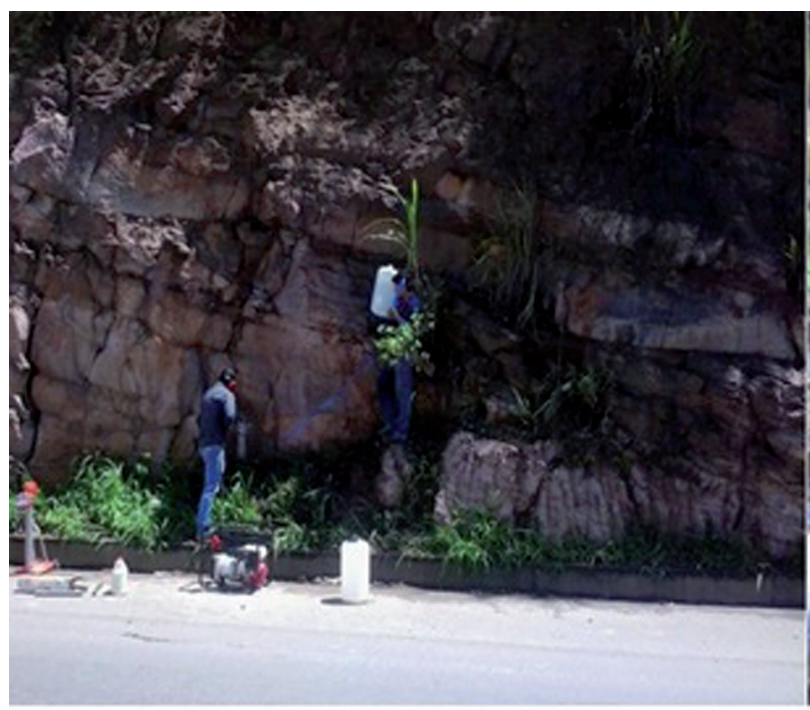

a.

FIGURA 4. a) Formación La Luna. b) Formación Tambor

Se seleccionó una muestra representativa de cada tipo; en el caso de la arenisca, sus dimensiones son de $39 \mathrm{~mm}$ de largo y de diámetro de 31,75 $\mathrm{mm}(1,25$ pulgadas); texturalmente, el tamaño de grano es medio (300-500 um). Según la clasificación de Folk (1974), composicionalmente es conformada por $95 \%$ de cuarzo, $3 \%$ de feldespato y $2 \%$ fragmento de roca, definiéndose como cuarzo arenita de grano medio bien calibrada. El plano de la microfractura atraviesa la roca prácticamente de manera transversal, siendo ésta parcialmente abierta y seca, con apertura de $0,39 \mathrm{~mm}$ (FIGURA 5).

La caliza (FIGURA 6) tiene dimensiones de $54 \mathrm{~mm}$ de largo y de igual diámetro que la arenisca. La microfractura presente, de apertura de $0,99 \mathrm{~mm}$, hace parte de una red de fracturas con contenido orgánico (petróleo bituminoso) que de acuerdo con Liu et al. (2013) puede tener un origen asociado a la sobrepresión y con eventos relacionados a la compresión tectónica de la zona y el consecuente levantamiento de la Cordillera Oriental colombiana.

Para validar la técnica de tomografía propuesta en esta investigación se crearon una serie de plugs sintéticos de concreto, hechos de cemento blanco comercial, con una relación agua-cemento de 0,45 (FIGURA 7). Se simula la detección de discontinuidades de un medio a través de las inclusiones huecas y la matriz dura de cemento blanco, respectivamente. Con este ejercicio se valida la congruencia de ubicación de las discontinuidades y el cálculo de densidad de inclusión, este último se aplicará posteriormente como densidad de microfractura en las muestras reales.
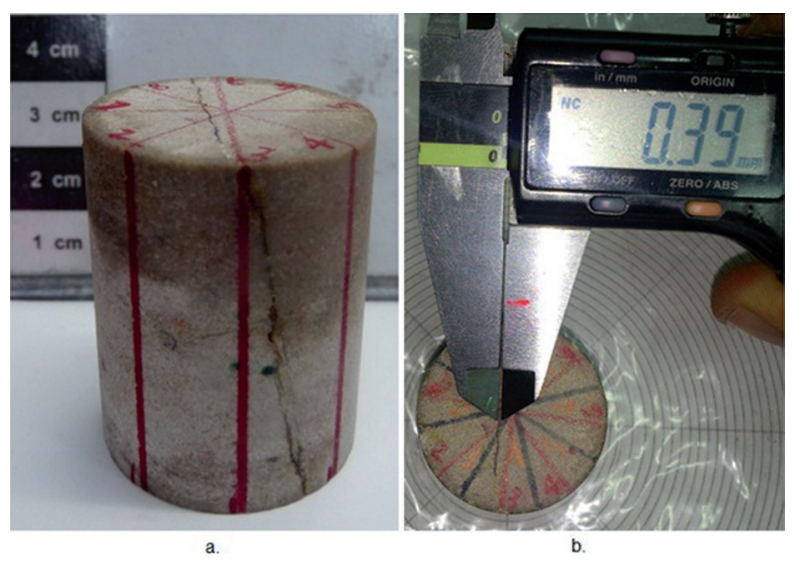

FIGURA 5. a) Arenisca microfracturada seleccionada. b) Apertura de la microfractura

\section{Montaje y Adquisición del Tiempo de Viaje}

El montaje de la técnica es descrito esencialmente en el diseño de la metodología. Tanto en la arenisca como en la caliza se marcaron las posiciones donde se ubican los ocho cristales cada $45^{\circ}$ (ver FIGURA 3), para mantener dichas posiciones cuando se desmonte la abrazadera de cristales PZT se realizaron unas líneas que se proyectan verticalmente, de igual manera se marcaron cuatro niveles horizontales, el primer nivel a una longitud de $6 \mathrm{~mm}$ del borde superior ya que es el ancho de la abrazadera y los otros tres a $3 \mathrm{~mm}$ para un barrido total vertical de $15 \mathrm{~mm}$ (FIGURA 8). 

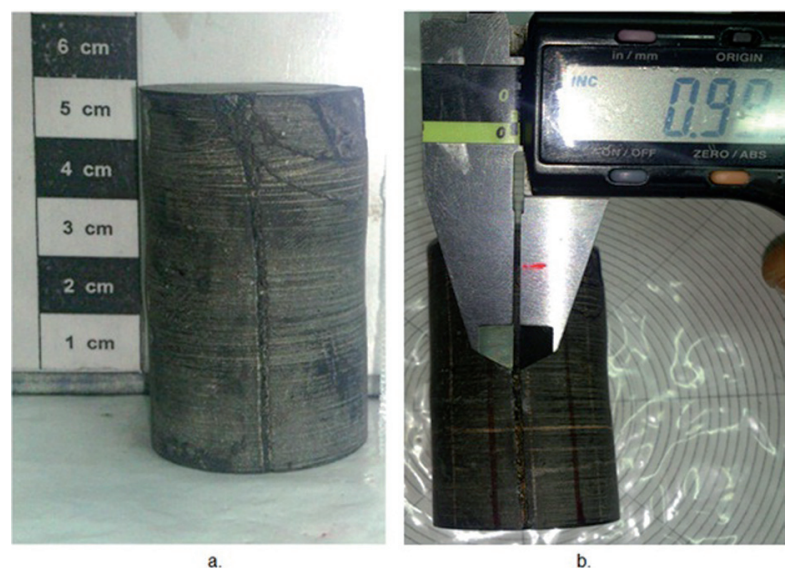

FIGURA 6. a) Caliza microfracturada seleccionada. b) Apertura de la microfractura

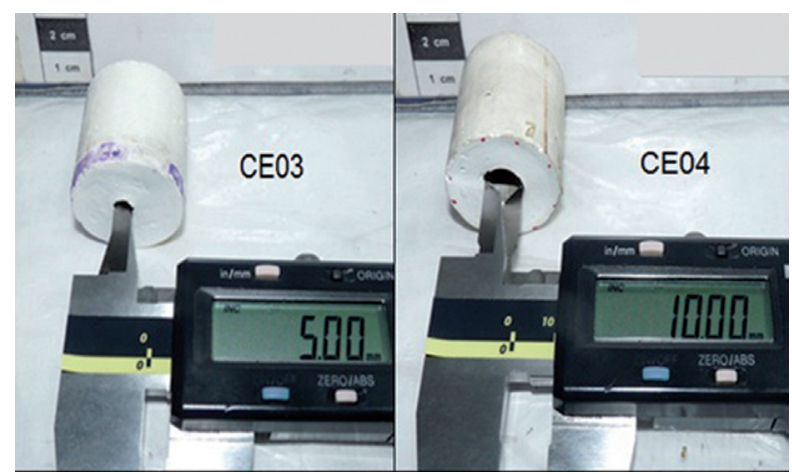

FIGURA 7. Plugs sintéticos de concreto

Se instalan los cables que conectan el pulsador a los cristales de PZT y estos al osciloscopio. El primer cristal emisor es el PZT 1, por ende, el cable tipo caimán proveniente del pulsador es conectado manualmente a este; por otro lado, el cristal receptor es el PZT 2 y de igual manera se conecta el cable que se dirige al osciloscopio. Una vez hecho el montaje se activa el pulsador y se cuantifica el tiempo de propagación de la trayectoria PZT 1-PZT 2; éste es medido en el software TEKTRONIX ${ }^{\circledR}$; de igual manera, es cuantificado cada uno de los tiempos de las 56 trayectorias hasta llegar a la trayectoria PZT 8 - PZT 7, con este proceso se completa un nivel (corte transversal).

Para optimizar la calidad de la señal se utilizó grasa de vacío entre la abrazadera y la muestra, esto con el fin de disminuir el ruido. El ajuste entre la abrazadera y muestra fue asegurado con una pinza de muselina, esto permite tener una señal estable y con gran amplitud (FIGURA 9).
Adquiridas todas las señales de un nivel se procede a correr verticalmente la abrazadera, desmontándola, abriendo la pinza de muselina y ubicándola en el siguiente nivel; de esta manera se adquiere la información acústica a lo largo la de muestra.

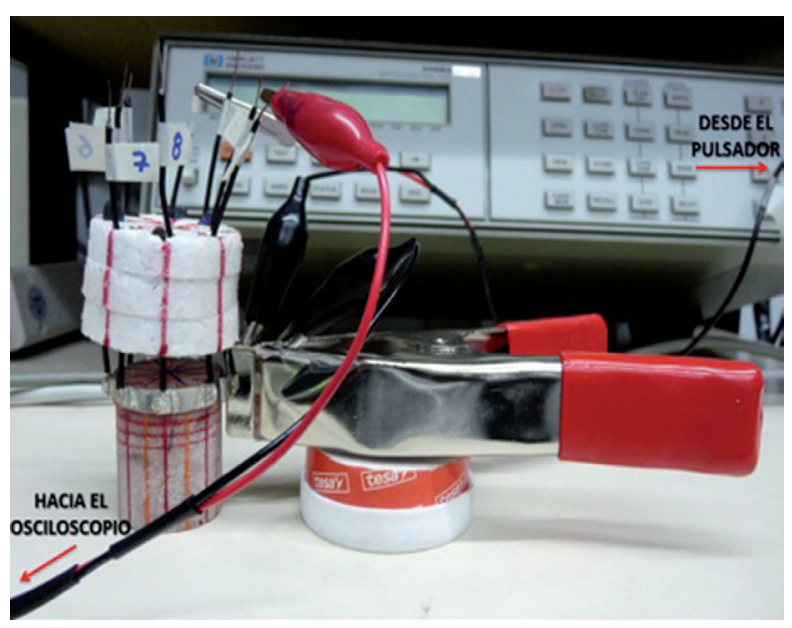

FIGURA 8. Montaje prueba ultrasónica.

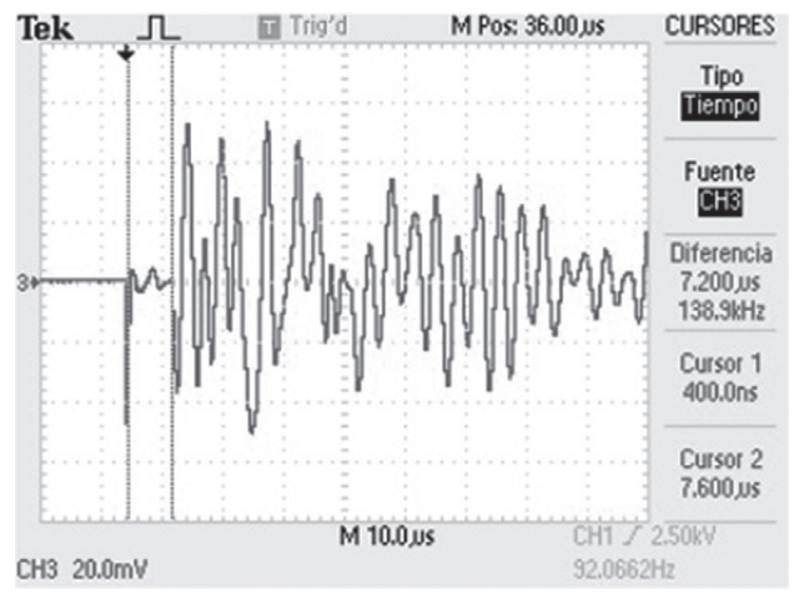

FIGURA 9. Señal acústica obtenida por el montaje.

\section{Calculo distancia de trayectorias}

Se planteó una plantilla en Excel (TABLA 1) con el fin de calcular la posición de cada uno de los puntos donde son ubicados los cristales PZT, esta se hace con una circunferencia hipotética de diámetro igual que la muestra. En la plantilla la información de entrada son las celdas verdes y la información generada son las celdas azules (TABLA 1). La plantilla efectivamente grafica la circunferencia hipotética (FIGURA 10), donde se visualiza la posición de cada uno de los cristales PZT. 
La distancia entre los puntos equivalente a la distancia de las trayectorias de las señales es calculada a partir de la ecuación 1:

$$
d=\sqrt{\left(x_{2}-x_{1}\right)^{2}+\left(y_{2}-y_{1}\right)^{2}}
$$

Finalmente, se calcula cada una de las trayectorias numerándose respectivamente, en total son 56 (TABLA 2).

TABLA 1. Cálculo de Posiciones de cristales PZT.

\begin{tabular}{|c|c|c|c|c|c|c|c|}
\hline $\begin{array}{c}\text { Diámetro (D) } \\
\text { [in] }\end{array}$ & $\begin{array}{c}\text { Radio ( } r=D / 2) \\
\text { [in] }\end{array}$ & $\begin{array}{c}\text { Cristales Total } \\
\text { (CT) }\end{array}$ & $\begin{array}{l}\text { Delta Ángulo } \\
(\Delta \theta=360 / C T)\end{array}$ & N. Cristal & {$[\theta]$} & $\begin{array}{c}X= \\
r \operatorname{Cos} \theta\end{array}$ & $\begin{array}{c}\mathbf{Y}= \\
\mathbf{r S e n \theta}\end{array}$ \\
\hline \multirow{9}{*}{1.25} & \multirow{9}{*}{0.63} & \multirow{9}{*}{8} & \multirow{9}{*}{45} & 1 & 0 & 0,625 & 0,000 \\
\hline & & & & 2 & 45 & 0,442 & 0,442 \\
\hline & & & & 3 & 90 & 0,000 & 0,625 \\
\hline & & & & 4 & 135 & $-0,442$ & 0,442 \\
\hline & & & & 5 & 180 & $-0,625$ & 0,000 \\
\hline & & & & 6 & 225 & $-0,442$ & $-0,442$ \\
\hline & & & & 7 & 270 & 0,000 & $-0,625$ \\
\hline & & & & 8 & 315 & 0,442 & $-0,442$ \\
\hline & & & & 1 & 360 & 0,625 & 0,000 \\
\hline
\end{tabular}

TABLA 2. Calculo de las primeras siete trayectorias.

\begin{tabular}{cccc}
\hline Trayectoria & Transmisor & Receptor & $\begin{array}{c}\text { Distancia (d) } \\
\text { [in] }\end{array}$ \\
\hline 1 & 1 & 2 & 0,478 \\
2 & 1 & 3 & 0,884 \\
3 & 1 & 4 & 1,555 \\
4 & 1 & 5 & 1,250 \\
5 & 1 & 6 & 1,155 \\
6 & 1 & 7 & 0,884 \\
7 & 1 & 8 & 0,478 \\
\hline
\end{tabular}

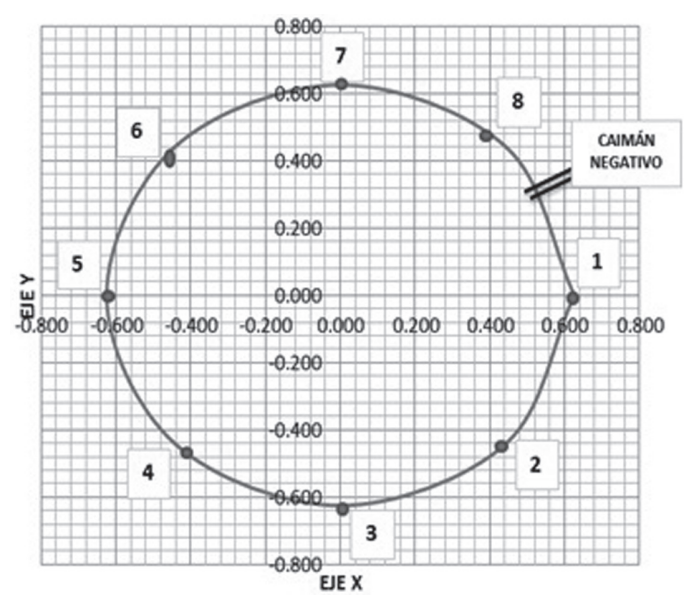

FIGURA 10. Circunferencia hipotética de la muestra.

\section{Cálculo de velocidad acústica}

Cada uno de los valores de las matrices numéricas están en función de la velocidad de onda acústica, para el cálculo de este parámetro se parte del cociente de la distancia de trayectorias entre PZT y de sus respectivos tiempos de viaje de la onda; sin embargo, los PZT no están adh eridos totalmente a la muestras, sino a la abrazadera de acero inoxidable, por lo tanto es importante calcular el tiempo de propagación de la onda dentro de este material que acústicamente ya está caracterizado (Tiempo Abrazadera), además se conoce su espesor. Posteriormente debe ser restado al Tiempo de Viaje Total (tvt) para obtener realmente en Tiempo de Viaje Roca (tvr), éste último es el que se tiene en cuenta para calcular la velocidad de onda al interior de la muestra. La TABLA 3 muestra parte de la plantilla hecha en Excel, la cual realiza los cálculos de velocidad para poder generar las matrices respectivas (TABLA 3).

\section{Procesamiento de los datos de Velocidad Acústica: Tomografía Acústica 3,5 D - Rocas Virtuales}

El objeto de crear "Rocas Virtuales", como ejercicio teórico y/o académico propio de esta investigación, a partir de datos de la literatura, es generar rutinas programadas en MATLAB que sirvan posteriormente para modelar las matrices de las rocas reales. Esta parte de la metodología describirá cualitativamente las rutinas programas en MATLAB. 
TABLA 3. Calculo de las velocidades acústicas de las primeras seis trayectorias

\begin{tabular}{|c|c|c|c|c|c|c|}
\hline \multicolumn{7}{|c|}{ CALCULO VELOCIDAD ONDA S: CALIZA - C01 } \\
\hline Trayectoria & $\begin{array}{l}\text { Tiempo de } \\
\text { viaje total } \\
\text { (tvt) }[\mathrm{s}]\end{array}$ & $\begin{array}{c}\text { Espesor } \\
\text { Abrazadera } \\
{[\mathrm{m}]}\end{array}$ & $\begin{array}{l}\text { Vel. Onda } S \\
\text { Acero }[\mathrm{m} / \mathbf{s}]\end{array}$ & $\begin{array}{c}\text { Tiempo } \\
\text { Abrazadera } \\
\text { (ta) }[\mathrm{s}]\end{array}$ & $\begin{array}{c}\text { Tiempo de Viaje } \\
\text { Roca (tvr=tvt- } \\
\text { ta) }[\mathrm{s}]\end{array}$ & $\begin{array}{c}\text { Vel. Onda S Roca } \\
\text { (d/tvr) }[\mathrm{m} / \mathrm{s}]\end{array}$ \\
\hline 1 & $9,00 \mathrm{E}-06$ & $2,00 \mathrm{E}-04$ & 3,200 & $6,25 \mathrm{E}-08$ & 8,94E-06 & $1.358,46$ \\
\hline 2 & $8,70 \mathrm{E}-06$ & $2,00 \mathrm{E}-04$ & 3,200 & $6,25 \mathrm{E}-08$ & $8,64 \mathrm{E}-06$ & $2.599,55$ \\
\hline 3 & $1,00 \mathrm{E}-05$ & $2,00 \mathrm{E}-04$ & 3,200 & $6,25 \mathrm{E}-08$ & 9,94E-06 & $3.974,54$ \\
\hline 4 & $1,20 \mathrm{E}-05$ & $2,00 \mathrm{E}-04$ & 3,200 & $6,25 \mathrm{E}-08$ & 1,19E-05 & $2.659,69$ \\
\hline 5 & $1,25 \mathrm{E}-05$ & 2,00E-04 & 3,200 & $6,25 \mathrm{E}-08$ & 1,24E-05 & $2.358,75$ \\
\hline 6 & $1,21 \mathrm{E}-05$ & $2,00 \mathrm{E}-04$ & 3,200 & $6,25 \mathrm{E}-08$ & $1,20 \mathrm{E}-05$ & $1.865,30$ \\
\hline
\end{tabular}

Al principio de esta investigación no se contaba con un software que procesara este tipo de datos (velocidades acústicas), por lo tanto, se crearon rutinas programadas en MATLAB que generarán multimatrices compuestas por 125 puntos coordenados o pixeles de posición, éstos a su vez forman un sistema tridimensional compuesto por columnas, filas y niveles en el eje $\mathrm{X}, \mathrm{Y}$ y Z, respectivamente (FIGURA 11).

A través de las multimatrices, estas rutinas permiten procesar las rocas virtuales en 3,5 D; se utilizan los datos que resultan a partir de velocidades de onda $\mathrm{P}$ (Fourmaintraux, 1975) en función de la porosidad de roca de las tres litologías: arenisca, caliza y granito. Para este ejercicio se seleccionó la tendencia de los datos de la arenisca (FIGURA 12).
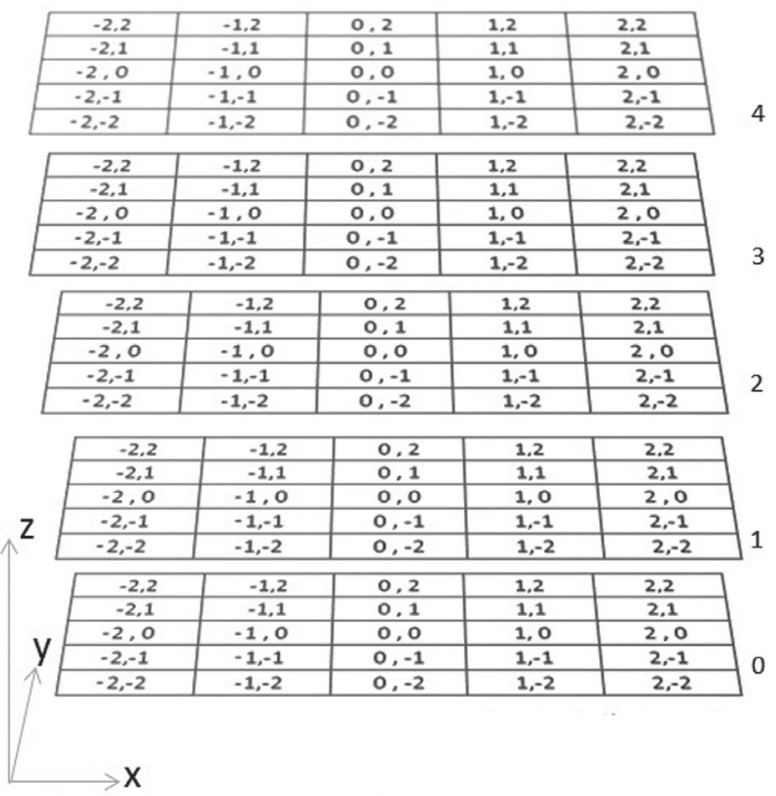

FIGURA 11. Estructura de matriz multidimensional en MATLAB

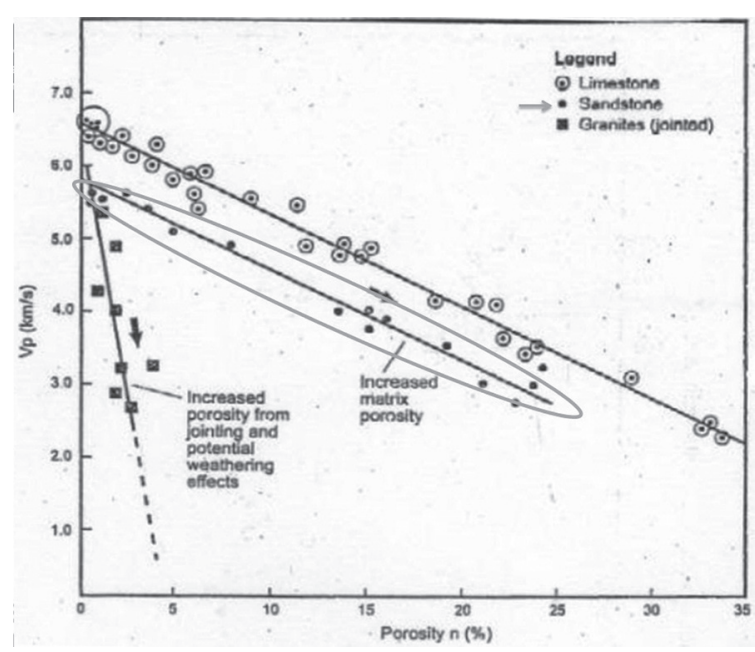

FIGURA 12. Grafica modificada con los resultados obtenidos de Fourmaintraux (1975). Velocidad de Onda P $(\mathrm{Vp})$ en función de la porosidad de la roca arenisca, tendencia subrayada.

El procesamiento de las rocas virtuales en 3,5 D se realizó bajo las siguientes suposiciones:

1. La tomografía acústica $3,5 \mathrm{D}$ de las rocas virtuales solo mostrará la parte matricial y microfracturada de la roca.

2. Las microfracturas son generadas con el valor de la velocidad de onda $\mathrm{P}$ en el aire a condiciones normales, es decir, $356 \mathrm{~m} / \mathrm{s}$.

3. La matriz rocosa es generada con los valores de velocidad de onda P correspondiente a la porosidad seleccionada de la FIGURA 12.

4. La relación porosidad vs microfractura es 1:1, es decir, cada unidad porcentual de porosidad de la FIGURA 12 , corresponde a una unidad o pixel de posición de la multimatriz que representará a la microfractura. Para el caso de una roca virtual creada a partir de 
los datos de porosidad de $5 \%$, se modificaran cinco pixeles de posición de la multimatriz con velocidad de onda $\mathrm{P}$ del aire y los demás pixeles de posición con la velocidad de onda $\mathrm{P}, 5.100 \mathrm{~m} / \mathrm{s}$, correspondiente a la porosidad de $5 \%$ de la FIGURA 12; de igual manera se hace para la demás rocas virtuales.

5. Las microfracturas son paralelas y se construyen a partir pixeles de posición en forma continua para simular la visualización de una discontinuidad en un medio.

En definitiva, se realizaron tres tipos de rocas virtuales a partir de porosidades de $0 \%, 5 \%$ y $25 \%$, las cuales corresponden a velocidades de onda $\mathrm{P}$ de $5.800 \mathrm{~m} / \mathrm{s}$, $5.100 \mathrm{~m} / \mathrm{s}$ y $2.800 \mathrm{~m} / \mathrm{s}$, respectivamente.

Esta rutina, además de procesar las imágenes en 3,5 D, también determina cuantitativamente la densidad de microfractura $D m f$. En este trabajo, $D m f$ se define como la relación del volumen de las microfracturas respecto al volumen total de la muestra de roca estudiada. La ecuación 2 representa la expresión matemática de Dmf:

$$
\text { Dmf }=\frac{\text { Vol } m f}{\text { Vol. Total Roca }} \times 100[\%]
$$

Aplicando la ecuación 2, se genera los siguientes resultados (TABLA 4):

TABLA 4. Calculo de la densidad de microfractura (Dmf) en rocas virtuales.

\begin{tabular}{cccccc}
\hline $\begin{array}{c}\text { ROCA } \\
\text { VIRTUAL }\end{array}$ & $\begin{array}{c}\text { POROSIDAD } \\
\text { FOURMAINTRAUX }\end{array}$ & $\begin{array}{c}\text { UNIDADES } \\
\text { VOLUMEN } \\
\text { TOTAL (UVT) }\end{array}$ & $\begin{array}{c}\text { UNIDADES DE } \\
\text { MICROFRACTURAS } \\
\text { (UM) }\end{array}$ & $\begin{array}{c}\text { UNIDADES DE } \\
\text { MATRIZ (UVT-UM) }\end{array}$ & $\begin{array}{c}\text { Dmf [\%] ((UM/ } \\
\text { UVT)*100) }\end{array}$ \\
\hline 1 & $\varphi=0 \%$ & 125 & 0 & 125 & 0 \\
2 & $\varphi=5 \%$ & 125 & 5 & 120 & 4,2 \\
3 & $\varphi=25 \%$ & 125 & 25 & 100 & 25 \\
\hline
\end{tabular}

Operativamente, la rutina programada en MATLAB asigna un valor de velocidad de onda $\mathrm{P}$ a cada uno de los pixeles de posición que conforman las tres rocas virtuales que se crearon, posteriormente interpola estos valores entre los pixeles. Para relacionar los valores de velocidad con los colores de la imagen se programa un gradiente de colores, en el que las velocidades altas (matrices de la roca) corresponden al color rojo y las velocidades bajas (microfracturas) corresponden al color azul. Finalmente, se obtienen los siguientes tomogramas 3,5 D cúbicos (FIGURA 13) que representan el ejercicio académico de la tomografía acústica $3,5 \mathrm{D}$ de las rocas virtuales:

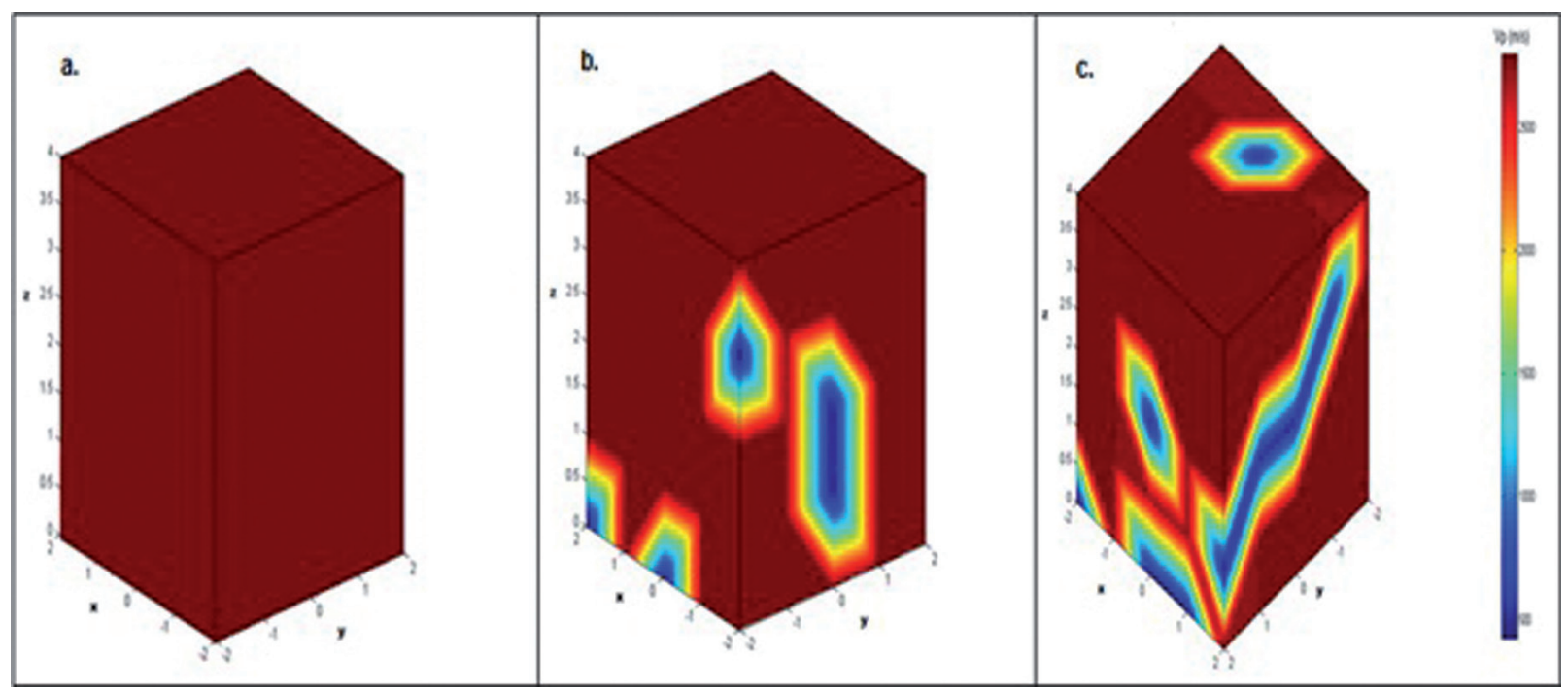

FIGURA 13. Rocas Virtuales 3,5 D. a) Roca Virtual 1. b)Roca Virtual 2. c)Roca Virtual 3.

Las tres rocas virtuales respecto a los resultados de Fourmaintraux (1975) de la FIGURA 12, guardan la relación de: a mayor discontinuidad de un medio, sea porosidad, fractura, microfracturas, vugs, etc, la velocidad de onda $\mathrm{P}$ registrada del material analizado disminuye, ya que a mayor discontinuidades dentro del material específico la densidad disminuye, y a su vez, ésta es función directa de la velocidad de onda P. 


\section{Procesamiento de los datos de Velocidad Acústica: Tomografía Acústica 3,5 D - Rocas Reales}

A diferencia de las rocas virtuales, la aplicación de la tomografía acústica 3,5 D en rocas reales consiste en modificar el dominio cubico en cilíndrico debido a que ésta es la geometría real de las rocas una vez extraídas del afloramiento, sin embargo, la base del procesamiento de esta aplicación es la rutina programada para las rocas virtuales.

Procesar el dominio cilíndrico de este tipo de imágenes tomográficas implicó crear una segunda rutina llamada "Circular_Domain", la cual convierte las matrices cuadradas generadas del proceso de adquisición acústica de las rocas obtenidas (explicado en Metodología Montaje y adquisición del tiempo de viaje) en matrices circulares, para posteriormente transformarlas en dominios cilíndricos en 3 D (FIGURA 14).

Una vez creado el dominio cilíndrico, se ejecuta el mismo proceso hecho en las rocas virtuales: interpolar entre puntos y planos para el suavizar el tomograma 3,5 D, en este caso, la interpolación es ejecutada mediante comando surf de MATLAB; crear el gradiente de velocidades de onda $\mathrm{S}$; y visualización de la tomografía acústica 3,5 D en geometría cilíndrica (Ver RESULTADOS).

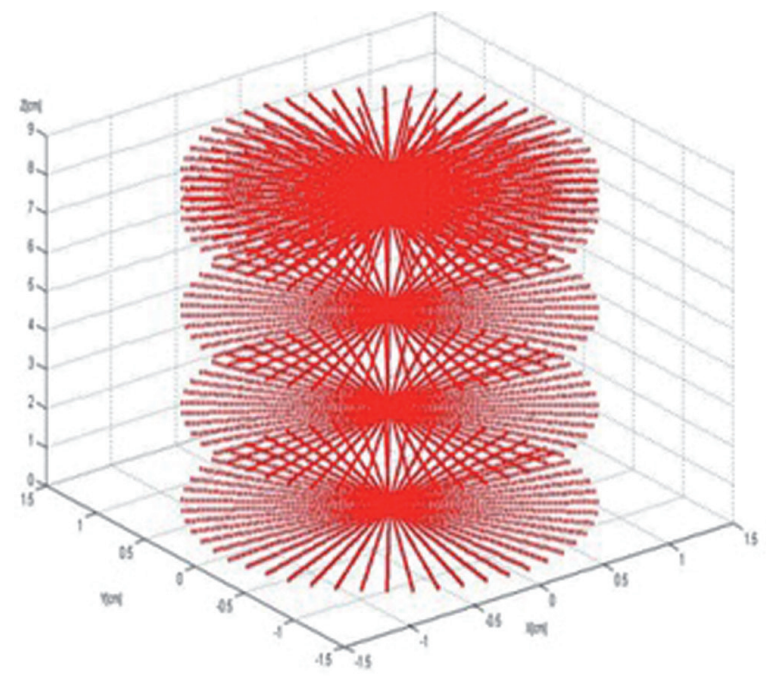

FIGURA 14. Enmallado 3D cilíndrico obtenido a partir de la rutina "Circular_Domain".

\section{RESULTADOS}

Los primeros resultados que se obtienen son matrices bidimensionales generadas individualmente en tomogramas acústicos 2,5 D de velocidad de onda $\mathrm{S}$.
Es importante analizar cada uno por separado ya que la tendencia de las microfracturas (discontinuidades) debe coincidir con la realidad física de la muestra. Una vez hecho este análisis se procede a ubicar cada uno de los tomogramas en el eje Z para generar el Tomograma Acústico 3,5 D y por ende cuantificar la densidad de microfractura.

\section{Tomografía Acústica 3,5 D: arenisca}

La FIGURA 15 corresponde a tomogramas acústicos 2,5 D obtenidos en los cuatro niveles de la muestra arenisca (FIGURA 5). Esta arenisca cuarzosa presenta una microfractura que la atraviesa en un plano casi vertical alrededor de $10^{\circ}$ de desviación (referencia vertical), se extiende desde PZT 3 hasta la inmediación de PZT 7 y 8 (FIGURA 15a).

El gradiente (rango) de velocidades de onda $\mathrm{S}$ generado por la rutina oscila entre 1.200 y $1.550 \mathrm{~m} / \mathrm{s}$; sin embargo, la gama de colores está entre amarillo verdoso, amarillo y rojo. Se puede observar que las tonalidades rojas corresponden a la matriz cuarzosa de la arenisca con velocidad cercana a los $1.550 \mathrm{~m} / \mathrm{s}$ y las tonalidades amarillas marcan la tendencia de la microfractura, más no su estructura finamente definida, con velocidades entre 1.390 y $1.425 \mathrm{~m} / \mathrm{s}$. De igual manera, la tendencia de la microfractura coincide con las posiciones descritas en la realidad física de la roca. En las demás figuras (15b, 15c y 15d), las cuales corresponden a los niveles 2,3 y 4 , respectivamente, se observa claramente la misma tendencia; sin embargo, a medida que la abrazadera va bajando, la tonalidad amarilla tiende a desaparecer; eso se debe a la presencia de precipitación inorgánica(cemento) que permite que todo el volumen de la muestra esté íntegro y no se separe por el plano de microfractura; éste cemento permite propagar la onda como si fuera un medio continuo, es decir, matriz rocosa.

La rutina finalmente fue adaptada para que los tomogramas acústicos 2,5 D sean ubicados en el eje $\mathrm{Z}$ de acuerdo al orden de muestreo vertical (niveles), de esta manera se obtiene las imágenes o tomogramas acústicos en 3,5 D, en este caso la visualización es externa (FIGURA 16) y se logra generar la tendencia que tiene la microfractura en la realidad física de la arenisca (FIGURA 5). De igual manera, se puede visualizar las microfracturas internamente (FIGURA 17); de esta manera se puede confirmar la presencia de precipitación de cemento al interior de la microfractura. 


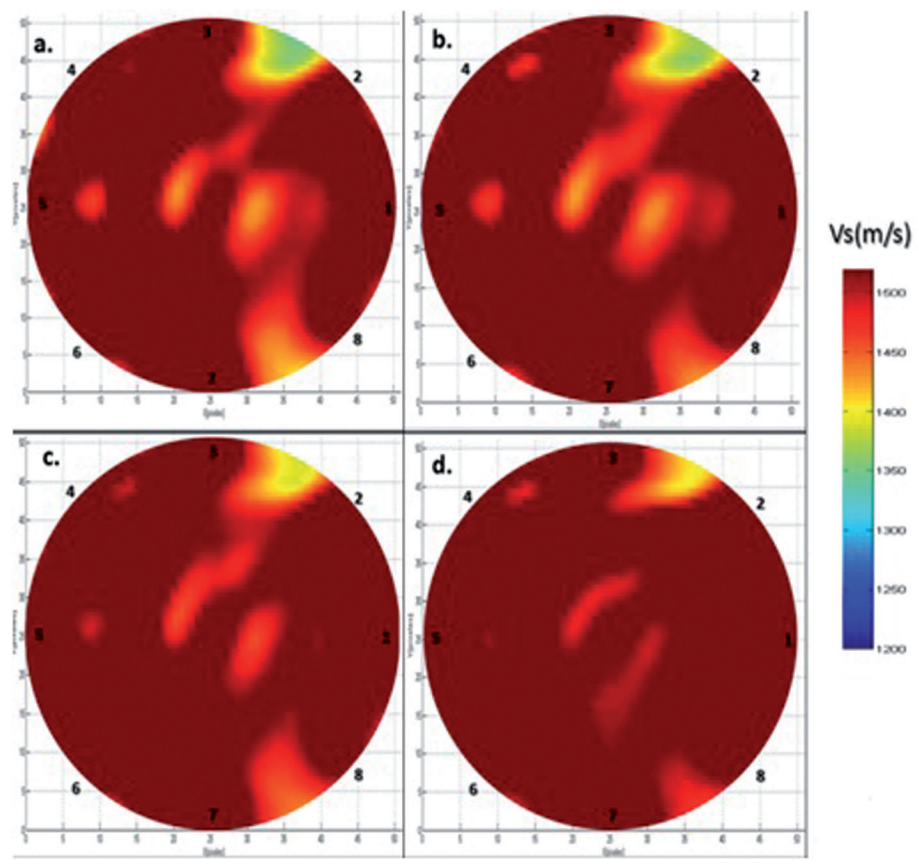

FIGURA 15. Tomografía Acústica 2,5 D Arenisca. a) Nivel 1. b) Nivel 2. c) Nivel 3. d) Nivel 4.

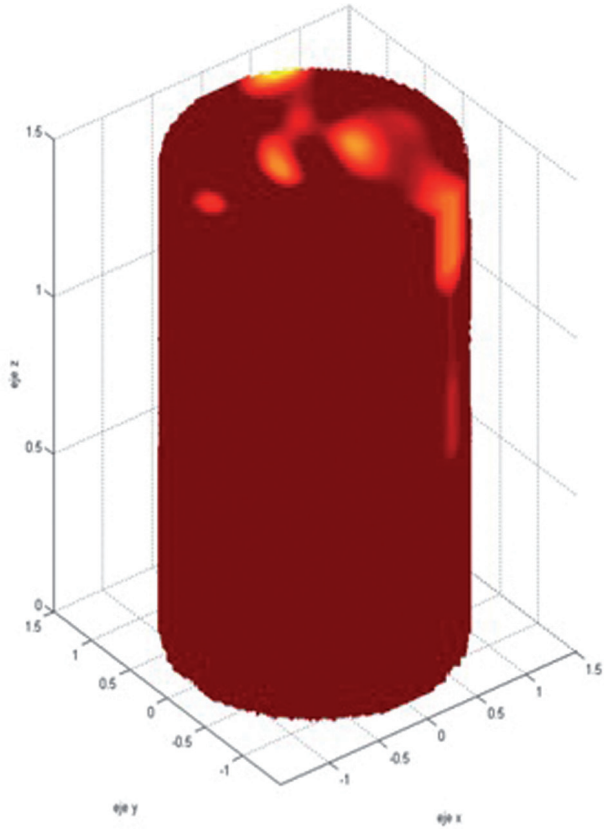

FIGURA 16. Tomografía Acústica $3,5 \mathrm{D}$, visualización externa de la Arenisca.

Estimación de la Densidad de Microfractura: arenisca.

Para el cálculo de este parámetro se programó una tercera rutina que cuente el número de celdas de la multimatriz 3,5 D que tenga valores de velocidad de microfracturas (velocidades bajas, rango estimado por

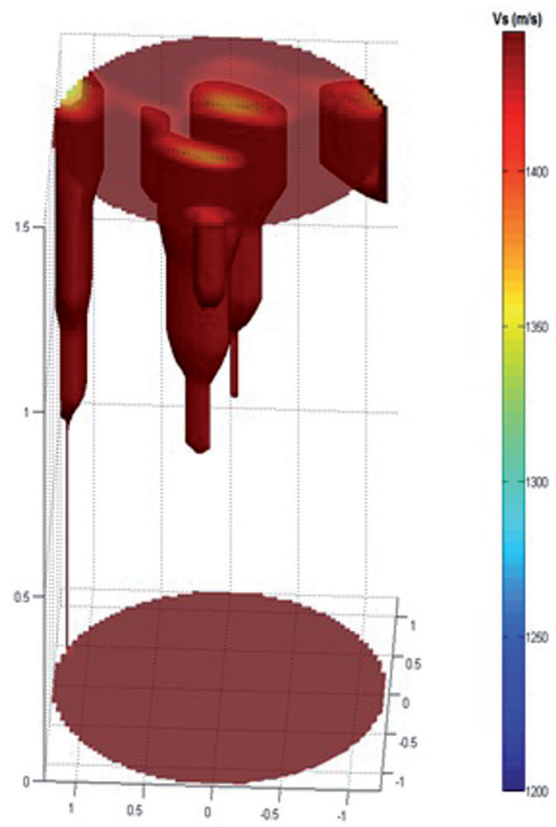

FIGURA 17. Tomografía Acústica 3,5 D interna de la Arenisca.

el análisis del usuario). Se puede optar por un rango de velocidad a consideración del ejecutor de la rutina ya que ésta no es de valor puntual.

Esta rutina llamada "DensMicro" se ha basado en la ecuación 2. Los datos de entrada son el nombre de la multimatriz 3,5 D y la velocidad a la cual por debajo 
de este valor se quiere cuantificar las celdas (velocidad de onda - microfracturas), entregando un valor $h$ como valor porcentual de densidad de microfractura. La velocidad de onda $\mathrm{S}$ para las microfracturas de la arenisca se estableció en un máximo de 1.400 $\mathrm{m} / \mathrm{s}$. El ejecutable (FIGURA 18) de esta rutina calcula esté parámetro en $1,0216 \%$ de volumen de microfractura.

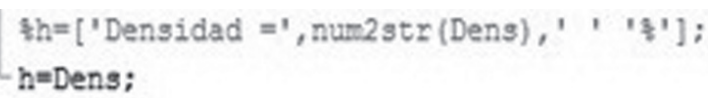

FIGURA 18. Aplicación rutina DensMicro - Arenisca

\section{Tomografía Acústica 3,5 D: caliza.}

El gradiente de velocidades de onda $\mathrm{S}$ generado para esta muestra oscila entre 1.350 y $1.780 \mathrm{~m} / \mathrm{s}$. Se visualizan tonalidades de color amarillo y rojo, donde le rojo representa la parte matricial calcárea con velocidad cercana a los $1.780 \mathrm{~m} / \mathrm{s}$ y la amarilla la microfractura y demás discontinuidades con velocidad alrededor de los $1.650 \mathrm{~m} / \mathrm{s}$.

Físicamente, la muestra está atravesada principalmente por un plano vertical de microfractura; sin embargo, también existen otros planos menores, tanto verticales como horizontales; la mayoría presentan contenido de material bituminoso (FIGURA19). En la FIGURA19a, se visualiza la vista superior de la muestra con la tendencia del plano de microfractura principal comprendida desde los puntos 3 - 2 y se extiende hasta los puntos $1-8$, esta tendencia es visible en los demás tomogramas acústicos 2,5 D (FIGURA 19a, 19b, 19c y 19d) con intensidad constante, diferente de los tomogramas acústicos 2,5 D de la arenisca (FIGURA 15).

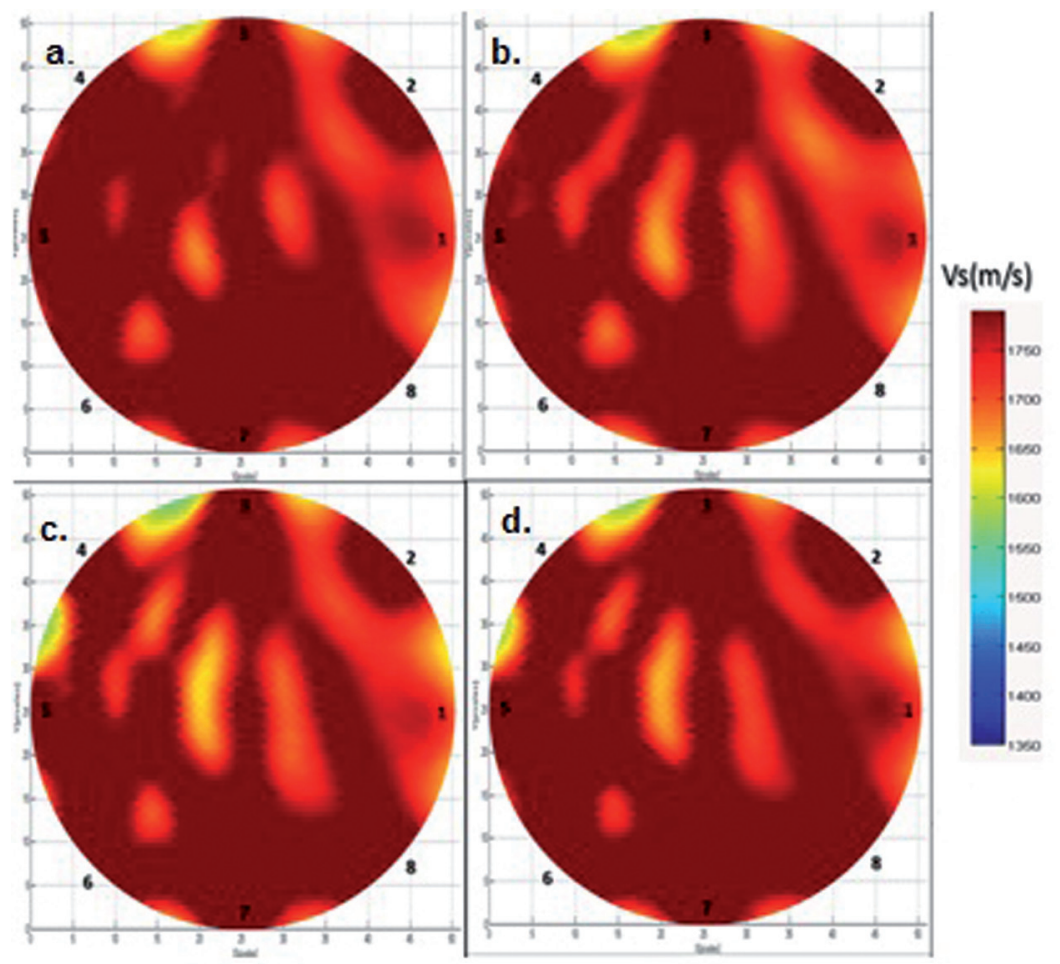

FIGURA 19. Tomografía Acústica 2,5 D Caliza. a) Nivel 1. b) Nivel 2. c) Nivel 3. d) Nivel 4.

Además del plano principal, también se logra visualizar la presencia otras anomalías de tonalidades amarillas que si varían con la intensidad de color y presencia menor en el tomograma de nivel 1 (FIGURA 19a) y mayor en el de nivel 4 (FIGURA 19d). Esto se asocia a la presencia de otras fracturas a nivel interno y al contenido del material orgánico (bitumen muy viscoso) que se refleja a medida que se realiza el barrido vertical. Es importante exaltar que la Formación La Luna es una de las principales formaciones generadoras de hidrocarburos del norte de Suramérica. 
La obtención del tomograma acústico 3,5 D de la muestra caliza (FIGURA 20) se obtuvo de igual manera que la arenisca. La FIGURA 20 muestra la visualización tomográfica externa, coincidiendo en gran parte con la realidad física de la muestra caliza (FIGURA 9).

La visualización tomográfica interna (FIGURA 21), efectivamente muestra una alta presencia de anomalías, que son asociadas a los planos secundarios de microfractura de la muestra (región superior) y al material orgánico ya mencionado.

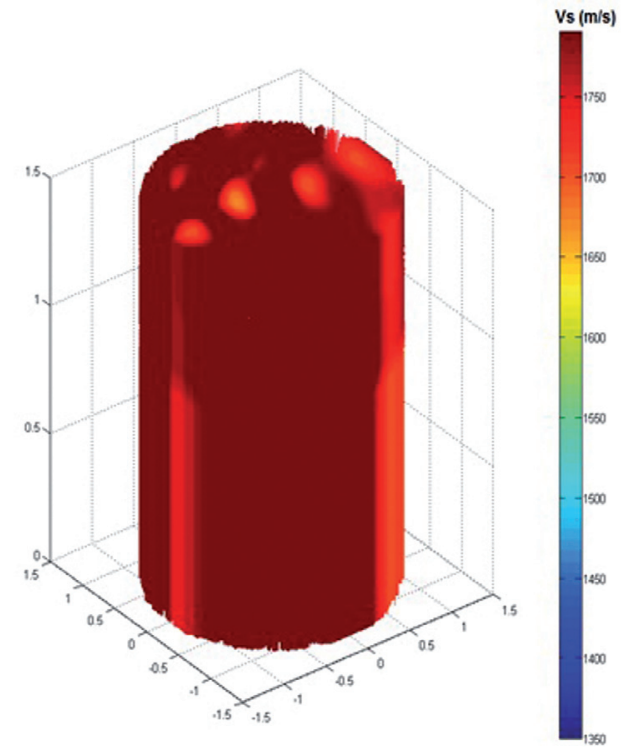

FIGURA 20. Tomografía Acústica 3,5 D externa de la Caliza.

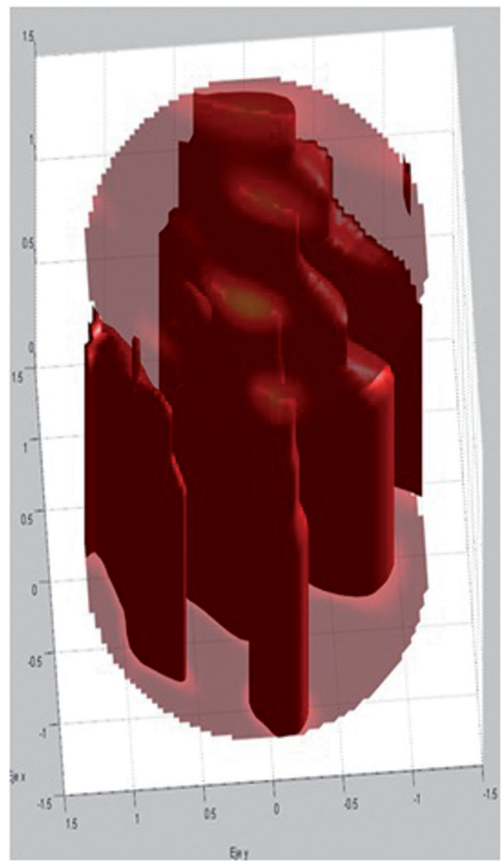

FIGURA 21. Tomografía Acústica 3,5 D interna de la caliza.

\section{Estimación de la Densidad de Microfractura Caliza C01: rutina Densmicro.}

La visualización interna de las muestras permite de manera a priori intuir de forma cualitativa la densidad de microfracturas, si es alta o baja. En el caso de la caliza, en la FIGURA 21, se puede intuir que es alta, comprobándose ésto en la aplicación de la rutina DensMicro (FIGURA 22), con un porcentaje de 28,0851 $\%$. Este parámetro, además del alto contenido orgánico presentado en esta muestra, refleja también la apertura de la microfractura que es mayor respecto a la arenisca.

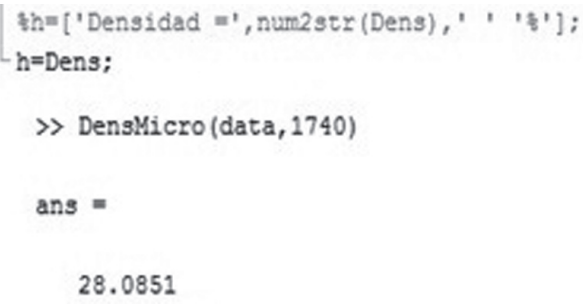

FIGURA 22. Aplicación rutina DensMicro - Caliza.

\section{VALIDACIÓN}

En este trabajo se decidió crear plugs sintéticos de concreto (FIGURA 10), cuya matriz es cemento blanco comercial con inclusiones generadas a través de caucho de geometría cilíndrica. Una vez endurecido el concreto se extrajeron los cauchos para dejar formadas las inclusiones huecas (airosas). La finalidad es obtener un tomograma 2,5 D correspondiente a cada plug sintético de concreto analizado, donde se pueda:

1. Medir las distancias en MATLAB de los diámetros de las inclusiones en los tomogramas acústicos 2,5 D y comparar respecto a los diámetros reales de las muestras.

2. Validar la rutina "DensMicro", en este caso, como "Densidad de Inclusión" por medio de la cuantificación del error asociado entre el cálculo la rutina y el cálculo real (cálculo teórico), ya que las geometrías tanto de la muestra como de la inclusión son regulares y definidas (circulo).

La validación asociada anteriormente se cuantificará por medio de porcentajes de error, siendo el valor experimental todo aquel que se obtenga de la metodología.

\section{Concreto CE04: 10 mm diámetro de inclusión}

Generado el Tomograma Acústico 2,5 D (FIGURA 23) de solo una sección transversal de la muestra CE04 (FIGURA 10), la rutina entregó un gradiente que oscila entre 1.890 a $1.690 \mathrm{~m} / \mathrm{s}$, cuyos colores marcan tonalidades de rojo 
a azul principalmente. La velocidad de onda S matricial del concreto está alrededor de los de los 1.750 y 1.890 $\mathrm{m} / \mathrm{s}$, y la de la discontinuidad de 1.690 y $1.700 \mathrm{~m} / \mathrm{s}$. En teoría la velocidad puntual de la discontinuidad debería ser de $0 \mathrm{~m} / \mathrm{s}$ en los pixeles de posición correspondientes a la inclusión, ya que la onda $\mathrm{S}$ no se propaga por medios fluidos; sin embargo, en realidad la onda sortea viajar por el contorno de la misma, aumentando su tiempo de viaje, por ende, disminuye la velocidad. En el centro del tomograma de la FIGURA 23 se puede observar la presencia de una discontinuidad cuya geometría tiende a ser circular en representación de realidad física; no obstante, debido al ajuste por parte de la pinza de muselina, se está ejerciendo más ajuste (fuerza) en la parte horizontal que vertical, es por eso que parece ser como una elipse; además, las discontinuidades en formas de manchas amarillas alrededor de la discontinuidad central son generadas debido a la presencia de vugs (burbujas de aire) que no pudieron salir en el periodo del fraguado.
Por medio de MATLAB se pueden medir las distancias entre puntos de una imagen, aplicado en este caso a los tomogramas acústicos. Teniendo en cuenta que el dominio que generan los tomogramas es de $51 \times 51$ pixeles, es decir que el diámetro en pixeles de la muestra es de 51 y este a su vez equivalente a $31,75 \mathrm{~mm}$ (1,25 pulgadas), todas las distancias fueron obtenidas en pixeles para luego ser convertidas en milímetros $(51$ pixeles $=31,75 \mathrm{~mm})$.

Se tomaron cuatro medidas a la discontinuidad central: horizontal D1 14,87 pixeles (FIGURA 23a); vertical D2 16,80 pixeles (FIGURA 23b); y dos diagonales, D3 15,23 y D4 16,02 pixeles, respectivamente (FIGURA 23c y 23d).

Para cuantificar el porcentaje de error se tomó como valor teórico el diámetro real de la inclusión, $10 \mathrm{~mm}$, y como valores experimentales las distancias obtenidas en el tomograma en función de pixeles para su posterior conversión en longitud real (TABLA 5).

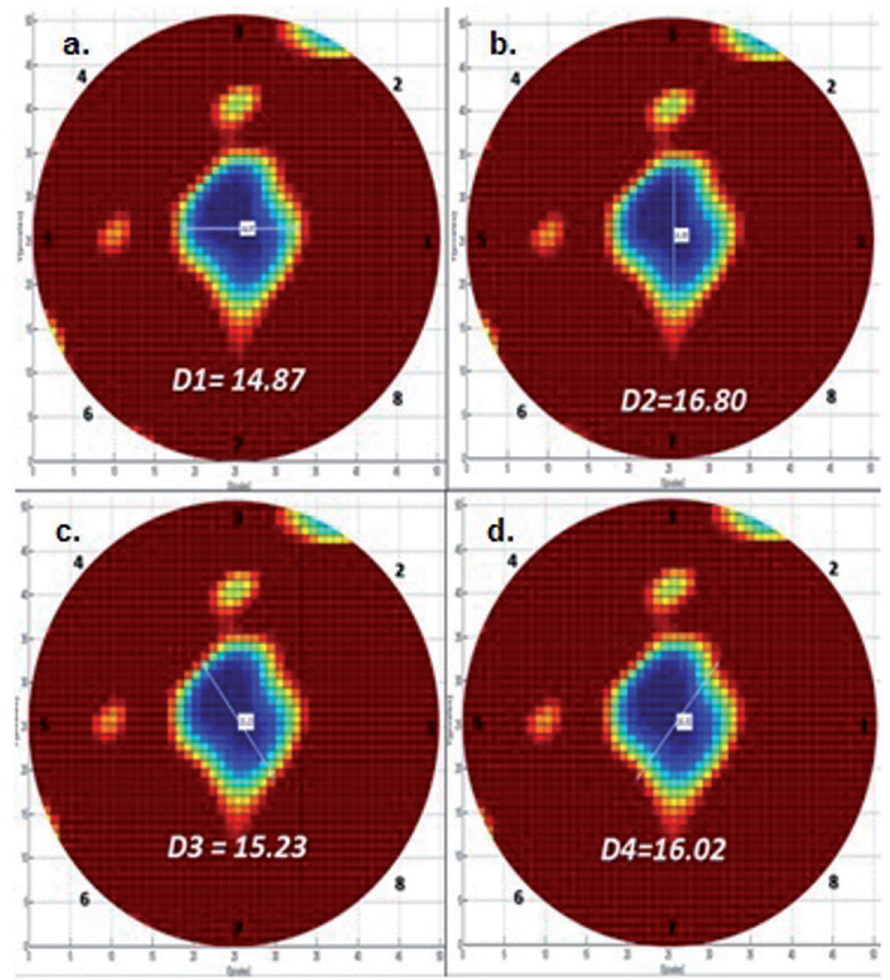

FIGURA 23. a) Dist. Horizontal. b)Dist. Vertical. c) Dist. 3 Diag. d) Dist. 4 Diag.

TABLA 5. Calculo de porcentaje de error distancias CE04.

\begin{tabular}{c|c|c|c|c|c|c}
\hline DISTANCIA & PIXELES & $\begin{array}{c}\text { FAC. } \\
\text { CONVERSIÓN } \\
\text { [31.57/51] }\end{array}$ & $\begin{array}{c}\text { MEDIDA REAL } \\
\mathbf{( m m )}\end{array}$ & $\begin{array}{c}\text { DIAMETRO } \\
\text { INCLUSIÓN (mm) }\end{array}$ & $\begin{array}{c}\text { ERROR } \\
\text { [\%] }\end{array}$ & $\begin{array}{c}\text { ERROR } \\
\text { PROMEDIO [\%] }\end{array}$ \\
\hline D1 & 14,87 & & 9,26 & & 7,43 & \\
D2 & 16,8 & 0,62 & 10,46 & 10 & 4,59 & 4,37 \\
D3 & 15,23 & & 9,48 & & 5,19 & \\
D4 & 16,02 & & 9,97 & & 0,27 & \\
\hline
\end{tabular}


Se obtuvieron los porcentajes de error de cada una de las distancias y se halló un promedio aritmético de 4,37\%, siendo éste un porcentaje muy bajo se ha considerado por parte de los autores que representa con certeza la realidad física de la muestra CE04; de esta forma se logra validar la instrumentación general de adquisición de señales acústica utilizada.

La rutina DensMicro ha sido aplicada a la matriz de velocidades acústicas de la muestra CE04 (FIGURA 24), los datos pedidos por esta rutina son el nombre de la hypermatriz cuando es 3,5 D o de la matriz cuando es $2,5 \mathrm{D}$ y de la velocidad máxima que caracteriza las microfracturas, en el caso de concreto CE04 el nombre de la matriz es ZZ1 y la velocidad máxima de microfractura es $1.696 \mathrm{~m} / \mathrm{s}$, como resultado la densidad de microfractura (inclusión airosa) en este caso es de $10,5729 \%$.

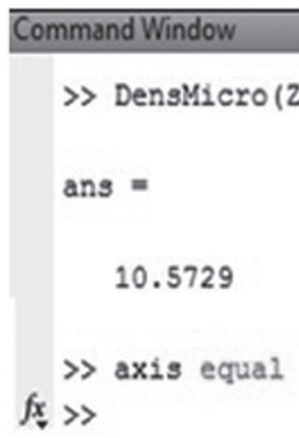

FIGURA 24. Rutina DensMicro aplicada a la matriz numérica de CE04.

\section{Concreto CE03: 5 mm diámetro de inclusión}

Obtenido el tomograma de la sección transversal de la muestra CE03 (FIGURA 7), la rutina entregó un gradiente que oscila entre 1.700 a $1.900 \mathrm{~m} / \mathrm{s}$, cuyos colores marcan tonalidades de rojo a amarillo principalmente. La velocidad de onda $\mathrm{S}$ matricial del concreto está alrededor de los de los 1.820 y $1.900 \mathrm{~m} / \mathrm{s}$ y la de la discontinuidad de 1.700 y 1.811 $\mathrm{m} / \mathrm{s}$. En el centro se puede observar la presencia de una discontinuidad que es de geometría elipsoidal representando tomográficamente la realidad física de la inclusión circular de $5 \mathrm{~mm}$ de diámetro.

Los efectos del ajustamiento de la pinza de muselina al igual que el tomograma CE04 se ven reflejados con igual intensidad afectando considerablemente la visualización. Como la inclusión no quedo totalmente vertical y centrada en la muestra, es posible que haya afectado; sin embargo, a la discontinuidad de mayor intensidad, de color amarillo, se le estudiarán sus dimensiones y se calculará la densidad de microfractura.

Al igual que la muestra CE04, se tomaron cuatro medidas a la discontinuidad central: horizontal D1 6,94 pixeles (FIGURA 25a); vertical D2 8,58 pixeles (FIGURA 25b); y dos diagonales, de 8,91 y 8,65 pixeles, respectivamente (FIGURAS 25c y 25d).

Cuantificando el porcentaje de error se tomó como valor teórico el diámetro real de la inclusión, $5 \mathrm{~mm}$, y como valores experimentales las distancias obtenidas en el tomograma en pixeles para su posterior conversión en longitud real (TABLA 6).

La TABLA 5 muestra que el porcentaje de error promedio de las distancias es de $9.76 \%$, siendo este porcentaje mayor que el anterior, esto es aceptable debido a que a medida que las microfracturas $o$ discontinuidades son más pequeñas se necesita mayor capacidad de resolución de la técnica de tomografía. Se puede aumentar la resolución utilizando PZT de altas frecuencias y mayor densidad de rayos de trayectorias (mayores cristales PZT en la abrazadera).

Aplicando la rutina DensMicro de la matriz es ZZ2 (concreto CE03), la velocidad máxima de microfractura es $1811 \mathrm{~m} / \mathrm{s}$, como resultado la densidad de microfractura en este caso es de $2.6543 \%$ (FIGURA 26).

TABLA 6. Calculo de porcentaje de error distancias CE03.

\begin{tabular}{c|c|c|c|c|c|c}
\hline DISTANCIA & PIXELES & $\begin{array}{c}\text { FAC. } \\
\text { CONVERSIÓN } \\
{[\mathbf{3 1 . 5 7 / 5 1 ]}}\end{array}$ & $\begin{array}{c}\text { MEDIDA REAL } \\
\mathbf{( m m )}\end{array}$ & $\begin{array}{c}\text { DIAMETRO } \\
\text { INCLUSIÓN } \\
\mathbf{( m m )}\end{array}$ & ERROR [\%] & $\begin{array}{c}\text { ERROR PROMEDIO } \\
\text { [\%] }\end{array}$ \\
\hline D1 & 6,94 & & 4,32 & & 13,59 & \\
D2 & 8,58 & 0,62 & 5,34 & 5 & 6,83 & 9,76 \\
D3 & 8,91 & & 5,55 & 5,94 & \\
D4 & 8,65 & & 5,39 & & 7,7 & \\
\hline
\end{tabular}




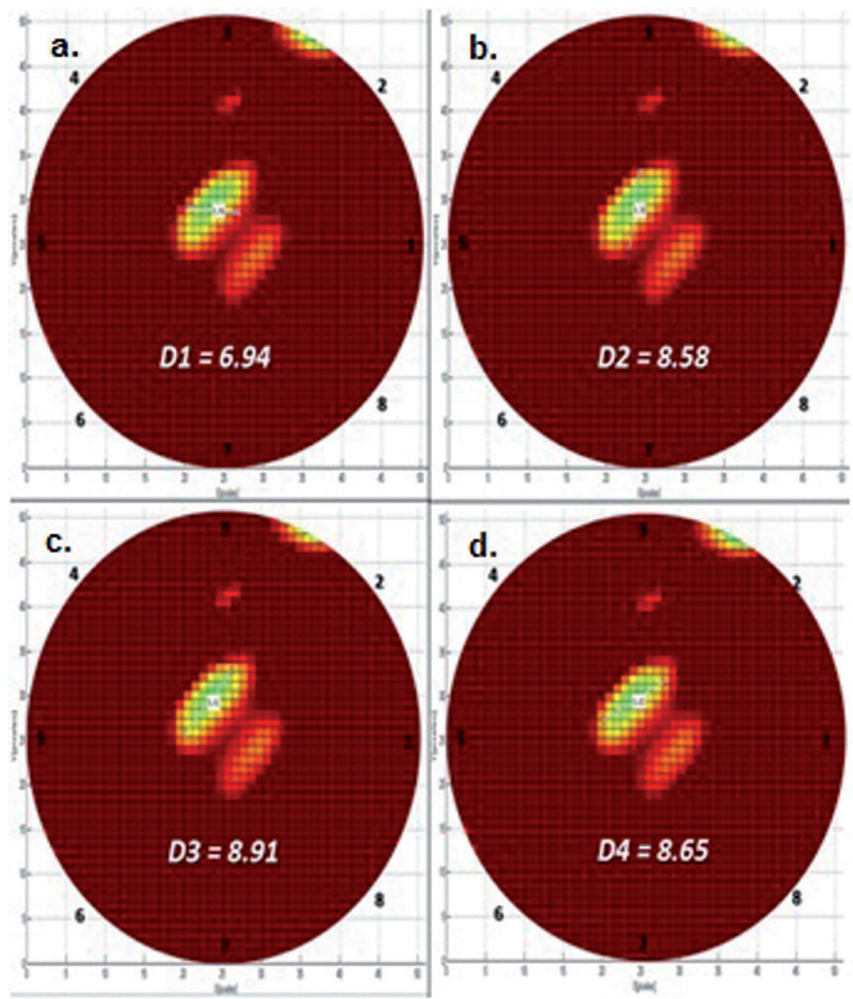

FIGURA 25. a) Dist. Horizontal. b) Dist.Vertical. c) Dist. 3 Diag. d) Dist. 4 Diag.

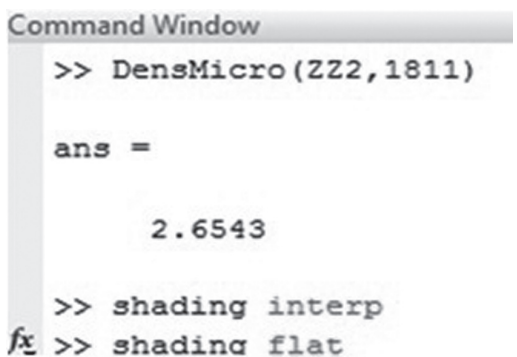

FIGURA 26. Rutina DensMicro aplicada a la matriz CE03.

\section{Concreto CE00: Sin inclusión}

Finalmente se tomó la adquisición acústica en el concreto CE00 (FIGURA 27), este se caracteriza por ser la muestra patrón que no presenta ningún tipo de inclusiones, es netamente cemento blanco en la totalidad de su volumen.

Acústicamente presenta una velocidad de onda $\mathrm{S}$ de alrededor de los $1900 \mathrm{~m} / \mathrm{s}$, el color que presenta es rojo en toda la imagen, esto significa la homogeneidad de la muestra en su interior; la anomalía presentada en una región de su límite se debe a defectos de borde de la adquisición acústica que normalmente se presentan en este tipo de pruebas. Para esta prueba no aplica la medición de distancias y la densidad de microfractura es $0 \%$.

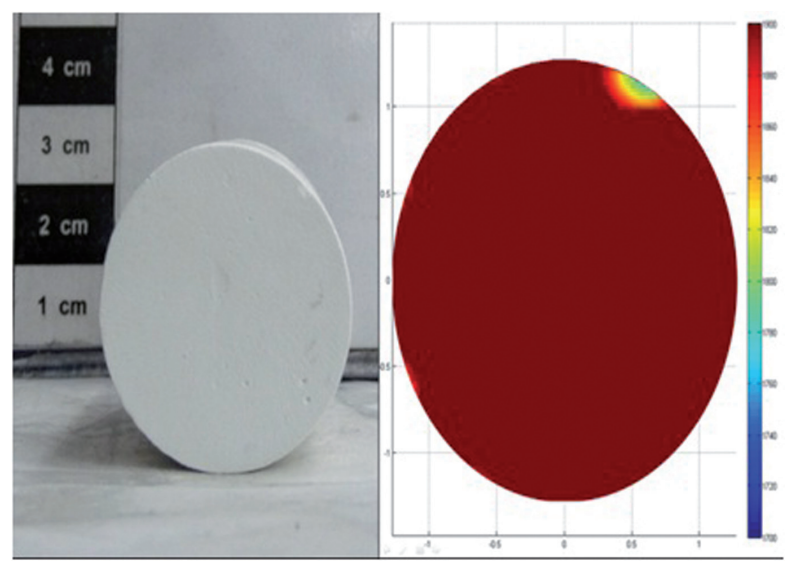

FIGURA 27. Concreto CE00 real y su respectiva Tomografía Acústica 2,5 D.

\section{Porcentaje de Error: Aplicación rutina DensMicro en los Plugs Sintéticos de Concretos.}

La cuantificación del porcentaje de error de esta rutina está en referencia al cálculo teórico de la densidad de inclusión de las muestras de concreto. Para poder aplicar la ecuación 2 , se ha tomado como volumen de inclusión el correspondiente a la sección cubierta por la abrazadera de adquisición acústica en la muestra de concreto, la altura corresponde al ancho de la abrazadera y el radio a la mitad del diámetro de la inclusión; para el 
volumen de la muestra de concreto (volumen concreto bruto), la altura corresponde también al ancho de la abrazadera y el radio a la mitad del diámetro de la muestra.

Una vez calculado el volumen de concreto bruto (volumen de inclusión más el volumen de la parte dura del concreto) y el volumen de inclusión, se pueden tener valores teóricos de densidad de inclusión(DIT); respecto a los valores de densidad de inclusión por medio de la rutina, se toman como valores experimentales (DIE).

En la TABLA 7, el porcentaje de error para la muestra CE04 obtenido es de 6,92 \% y el de la muestra CE03 es de $7,19 \%$. Estos resultados son muy aceptables debido a la visualización clara de la discontinuidad; sin embargo, la capacidad de resolución $0,62 \mathrm{~mm}$ para esta técnica, de acuerdo a la dimensión real del pixel, es muy importante ya que a medida que se disminuye la dimensión de la discontinuidad se dificultad la detección de la anomalía, es por eso que el porcentaje de error tiende a aumentar cuando el tamaño de la anomalía disminuye.

TABLA 7. Calculo porcentaje de error rutina DensMicro

\begin{tabular}{ccccc|c}
\hline $\begin{array}{c}\text { Plug } \\
\text { Sintentico }\end{array}$ & $\begin{array}{c}\text { Diam. } \\
\text { Inclusión }\end{array}$ & DIT & DIE & $\begin{array}{c}\text { Error } \\
{[\%]}\end{array}$ & $\begin{array}{c}\text { Error } \\
\text { Prom [\%] }\end{array}$ \\
\hline CE00 & 0 & 0 & 0 & -- & \\
CE03 & 0,5 & 2,47 & 2,65 & 7,09 & 7,06 \\
CE04 & 1 & 9,89 & 10,57 & 6,92 & \\
\hline
\end{tabular}

De esta manera se valida la metodología aplicada en esta investigación para cuantificar el parámetro de densidad de microfracturas en las rocas.

\section{CONCLUSIONES}

La técnica de tomografía acústica propuesta en esta investigación tiene viabilidad para el estudio físico interno de muestras a escala de laboratorio. Los resultados de los tomogramas de concretos así lo demuestran; sin embargo, el límite de resolución de esta técnica es de 0,62 mm, correspondiente a la dimensión real de un pixel.

La certidumbre del tiempo de viaje de las ondas acústicas generadas por los cristales piezoeléctricos depende de la calidad de la señal, y ésta a su vez de un buen montaje de instrumentación ultrasónica (cable coaxiales, ajuste de abrazadera, grasa de vacío, etc).

La utilización de modelos controlados como plugs sintéticos de concretos con inclusiones "huecas", a través de la variación del diámetro del mismo, permite sensibilizar la longitud de onda y tener patrones de referencias para validar los tomogramas.

Efectivamente, se demostró que la velocidad acústica de la onda S está relacionada directamente con la densidad del material, tal cual como lo dice la literatura.

La capacidad de resolución del tomograma se puede mejorar, principalmente así: subiendo la densidad de trayectorias que aumenta la cantidad de PZT en la abrazadera, disminuyendo la longitud de onda mediante la utilización de PZT con frecuencias mayores a $1 \mathrm{MHz}$ y ejecutando los tomogramas en equipos de computación de alta capacidad de procesamiento.

La importancia de la Densidad de Microfractura por medio de esta metodología, se proyecta en mejorar la caracterización de los modelos de YNF, evaluación de riesgo de exploración y optimización del tratamiento para la extracción de hidrocarburos.

\section{AGRADECIMIENTOS}

Los autores del presente artículo expresan sinceramente sus agradecimientos al convenio 001 de 2012 del Grupo de Investigación Estabilidad de Pozo, suscrito entre el Instituto Colombiano del Petróleo (ICP), centro de investigaciones de la Empresa Colombiana de Petróleos (ECOPETROL S.A.) y la Universidad Industrial de Santander (UIS); mediante el cual, se proyecta el perfeccionamiento de la técnica de Tomografía Acústica aplicada en el Laboratorio de Mecánica de Rocas del ICP. Así mismo a los geólogos Yesid Goyes y David Duarte por sus aportes en el modelamiento de imágenes en MATLAB y análisis de afloramientos, a la ingeniera Erika Contreras por la gestión de equipos de campo. A los dos árbitros anónimos de la revista Boletín de Geología por evaluar la calidad científica del artículo.

\section{REFERENCIAS}

Folk, R.L. 1974. Petrology of Sedimentary Rocks. The University of Texas, Austin. USA. 184p.

Fourmaintraux, D. 1975. Quantification des discontinuities des roches et des massifs rocheux. Rock Mechanics, 7: 83-100.

Hooker, J.N., Gale, J.F.W., Gómez, L.A., Laubach, S.E., Marrer, R., and Reed, R.M. 2009. Aperture-size scaling variations in a low-strain opening-mode fracture set, Cozzette Sandstone, Colorado. Journal of Structural Geology 31: 707-718. 
Imhof, A.L. 2008. Caracterización de arenas y gravas con ondas elásticas: tomografía sísmica en CrossHole. Tesis Doctoral. Universidad Nacional de Cuyo. Mendoza. República Argentina.

Liu, Ch., Zhang, R., Zhang, H., Yang, X., and Wang, J. 2013. Characteristics and origin of microfracture in Lower Cretaceous tight sandstone from Kuga foreland basin, NW China. Adapted from extended abstract prepared in conjunction with poster presentation at AAPG Annual Convention and Exhibition, Pittsburgh, Pennsylvania, May 19-22, 2013.

Potts, B.D., and Santamarina, J.C. 1993. Geotechnical Tomography: The effects of Diffraction. Geotechnical Testing Journal, 16(4): 510-517.

Rueda, J. 2006. Metodología para determinar densidad de microfracturas en rocas cuya matriz presenta baja anisotropía, a partir de parámetros anisótropos: aplicación a la Formación Mirador del campo Cupiagua, piedemonte llanero. Tesis Pregrado. Universidad Industrial de Santander. Bucaramanga, Colombia, 80p.

Trabajo recibido: junio 24 de 2014

Trabajo aceptado: febrero 6 de 2015 